\title{
Progression of color decision making in introductory design education
}

\author{
Sibel Ertez Ural ${ }^{1}$ [1) | Saadet Akbay ${ }^{2}$ (1) | Burçak Altay ${ }^{1}$
}

\author{
${ }^{1}$ Department of Interior Architecture and \\ Environmental Design, Faculty of Art, \\ Design and Architecture, Bilkent \\ University, Bilkent, Ankara 06800, \\ Turkey \\ ${ }^{2}$ Department of Interior Architecture, \\ Faculty of Architecture, Çukurambar Mah, \\ Çankaya University, Çankaya, Ankara \\ 06530, Turkey
}

\section{Correspondence}

Sibel Ertez Ural, Department of Interior Architecture and Environmental Design, Bilkent University, Faculty of Art, Design and Architecture, Bilkent, Ankara, 06800, Turkey. Email: ural@bilkent.edu.tr

\begin{abstract}
Color comprises both subjective and objective aspects within its contextual nature. Research on color design tends to explore this seemingly contradictory concerns from theoretical point of view, as well as architectural and design practice. The aim of this study was to observe subjective, intuitive or heuristic and objective, knowledge-based or analytical attitudes toward color in design education. In the study 84 introductory design students were surveyed progressively to understand their color decision criteria after completion of three 2-dimensional colored exercises, specific in terms of color education. Students' responses to open-ended questions were coded according to the 5 categories, under 2 decision making processes derived from the literature; heuristic approach: preferential and symbolic criteria, and analytic reasoning: formal, thematic, and systematic criteria. A distinction between associative and emotional aspects of symbolic criteria was also revealed by the data analysis. The findings showed a shift from heuristic responses to analytic reasoning, as expected. Additionally, it is also investigated that students not only used heuristic approaches but also analytical components (formal and systematic) of color decision making in varying degrees as well, even before any color subjects covered. Thematic color decisions became a major part of the students' design considerations upon completion of color subjects. The observed increase in the number of color criteria interrelated by the students' among almost all categories explicated a complex decision making process particularly in color design and education. These findings were expected to lead to some further understanding in color decision making in design.
\end{abstract}

\section{K E Y W O R D S}

basic design, color decision making, design, design education, introductory design education

\section{1 | INTRODUCTION}

In design, color is a design element and considered a part of visual composition and perception. On the one hand, design recognizes color from an objective, scientific, and knowledge-based point of view because of its visual, formal, and functional qualities. On the other hand, it has an intrinsic, intuitive quality of its own and is defined as subjective experience. ${ }^{1}$ Adams $^{2}$ stated that, color has inherent design challenges and opportunities because it is the most subjective of all the design elements.

According to Green-Armytage, ${ }^{3}$ "successful color design depends on the designer's [own] experience, but it also depends on the designer's knowledge." (p. 253). Although color knowledge for designers derives from various disciplines, it also derives from the color education in design education. ${ }^{3}$ Design education generally looks upon color as a scientific theory, and design students are expected to learn about color through a variety of traditional and objective methods. Color theories by Goethe, Itten, and Albers are generally the main sources of color education in the curricula of design/architecture schools. ${ }^{4}$ Whereas design students are mostly introduced to color during introductory design education. ${ }^{2,5,6}$ In introductory design education, students are also introduced to color design principles derived from many other color theories. ${ }^{7}$ 
According to O'Connor, ${ }^{8}$ rationalist, empiric and positivist color theories "have been superseded by post-positivism and constructivism" (p. 272). O'Connor argued against predictive methods of color theories and designated an interface between color and aesthetic response, where the aesthetic response of color is peculiar to each individual regarding age, gender, affective states, cultural backgrounds, and so on. ${ }^{8}$

Research that investigates the use of color in the context of architectural practice underlines intuitive, individual, and contingent initials of practitioners, ${ }^{9-11}$ in conjunction with theoretical knowledge. ${ }^{12,13}$ While the dynamics between the two seemingly contradictory views of color: (i) the intuitive and subjective perspective and (ii) the objective and theoretical standpoint, are overviewed and discussed, their reflections on color education also need to be studied.

The context of education comprises the exposition of knowledge to the students while expecting them to respond to this within their projects. Thus, the students' use of intuitive and subjective attitudes as well as the use of theoretical and analytic reasoning based on the imparted knowledge at later stages are expected in the students' own projects. Akbay $^{12}$ indicates in her study that, design students' intuitive, subjective, and heuristic attitudes toward color design appear first, and then decrease as analytic attitudes increase from students' color education, but they do not disappear altogether. However, the degree and content of analytic reasoning at the initial stages as well as the degree and content of intuitive and subjective attitudes at the later stages within a short-term progress is subject to further exploration. In this respect, prior to going into a better understanding of color education in design schools. It is valuable to explore the students' color decision making process. Accordingly, this study addresses the following questions:

1. How do freshman (basic) design students' intuitive and subjective attitudes affect their color design decisions?

2. How do freshman (basic) design students' theoretical and analytic reasoning affect their color design decisions?

3. How do students' intuitive, subjective, theoretical, and analytic responses change (remain, develop, or disappear) in the course of color education?

\section{COLOR DECISION MAKING IN INTRODUCTORY DESIGN EDUCATION}

Design is an activity consisting of solving design problems. Students' solutions, hence, to these problems are based on their aesthetic responses either about their discriminations and judgments ${ }^{14-16}$ or decision makings. ${ }^{17}$ Aesthetic judgements are considered as personal experiences including sym- bolic meanings, associations, feelings, emotions, preferences, likes/dislikes based on an individual's value system which cannot be always associated with consciousness. ${ }^{18}$ They are tacit, intuitive, and inherent in culture, education, age, gender, background experiences ${ }^{16,19}$ which rely on heuristic system processing. ${ }^{20}$ Aesthetic decision making, on the other hand, is considered as consciously controlled, effortful, deliberate, and dependent on acquiring and using abilities of an individual. It is rule-based, objective, explicit, central, and rational ${ }^{19,21}$ which depend on analytic system processing. ${ }^{20} \mathrm{Klaczynski}^{19}$ indicated that both a heuristic system and an analytic system are cognitive adaptations, and heuristic system processing can be augmented by knowledge, thinking, and reasoning.

Design education, especially introductory design education, aims to teach students the elements of design and the basic principles of organization through reasoning and by forming aesthetic responses. Farivarsadri ${ }^{22}$ stated that in learning the basic principles of visual communication and design language in their first year, design students develop a set of aesthetic responses that form a base for their education in subsequent years. Koyuncugil $^{23}$ claimed that students' aesthetic judgements may change as they progress through their design education and their problem-solving abilities-which will likely improve as they progress. Light ${ }^{1}$ supported this idea by stating that design students' intuition is in varying stages of development, and thus their subjective responses can be enriched and cultivated. Droste,${ }^{24}$ thus, summarized design education as a pair of opposites: "intuition [...] or subjective experience, and objective recognition" (p. 32). When personal values and preferences are explored through the design process, students are expected to transform them into theoretical and analytical sets of attitudes. Therefore, design itself intimates subjectivity and objectivity; it melds intuition and reason.

More or less, design students have a pre-acquaintance with color based on personal preferences, subjective experiences, and socio-cultural attributions. The preferences, symbolic meanings or symbolic values of color are being connected with the students' heuristic attitudes, whereas formal, expressive, or thematic and systematic attributes of color are grounded in analytic reasoning as a main concern of fundamental color education. ${ }^{12,19,20,25}$ In accordance, the categories in heuristic and analytic decision making can be reframed as follows.

$$
\left.\begin{array}{c}
\text { Preferential } \\
\text { Symbolic }
\end{array}\right\} \text { Subjective/Intuitive/Heuristic }
$$

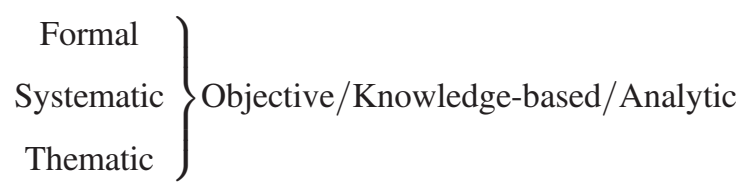

Hence, this study focuses on color while investigating the progression of interior design students' decision making process during their introductory design education. 


\section{3 | THE STUDY}

\subsection{The educational context}

The study was conducted in 2015-2016 fall semester, in the Interior Architecture and Environmental Design Department of Bilkent University in Turkey, within the curriculum of Basic Design Studio I. The educational method of the Department depends on the studio-based learning system. The 4-year undergraduate curriculum includes the Basic Design Studio I and II, 2 days in a week (4-h sessions) with a total of $8 \mathrm{~h}$ per week, in the first year and followed by Interior Design studio courses in consecutive 3 years. Each studio course in the curriculum is based on a project-based learning in which learning by doing and learning through practice are the pedagogical features. ${ }^{26,27}$ Basic Design Studio I is structured around the framework of elements and principles of design; ${ }^{2,28,29}$ with two-dimensional studies in the first half of the semester, followed by three-dimensional organizations in the second. Basic Design Studio II introduces architectural space as a continuation of the previously covered issues.

The first semester is composed of approximately 22 assignments (including 2- and 3-dimensional), where students are given an exercise either to be carried out in the studio or at home. The studio progresses with one-to-one critiques, formative and group critiques supported by feedback received to the students at the interim stages during development of each assignment according to the schedule and complexity of the project as well as summative critiques with formal assessment sessions where the project is graded at the final stage. During the progress, each student is expected to deal increasingly with visual problem solving with the acquired knowledge rather than previous knowledge and intuition. Thus, a rational, systematic, and consistent use of the learned "design language" which includes color theory and application is expected from the students and delivered to the students as such.

\section{2 | Material}

For the study, three 2-dimensional exercises which are assumed to be critical phases for the progression of color education were chosen. The subject of color was introduced in varying degrees in specific intervals during this progress. These exercises were assigned at the first, fourth, and seventh week (a total of 13 two-dimensional exercises were conducted) of a thirteen-week semester. The third exercise terminated basic studies on 2-dimensional organization and allowed progression into relief and three-dimensional exercises.

\subsection{1 | Exercise 1}

This exercise was assigned on the first studio day of the semester. The students were given a sketch problem without consulting any reference material or without the guidance or critique from the instructors within $4 \mathrm{~h}$ of the whole studio course. The students were asked to express the idea of order in a color composition on an A3 format drawing paper. They were free to use any colored material, that is, paper, magazine cut-outs, markers, and so on. This exercise aimed to familiarize students with the elements and concepts of basic design studio course, as well as to determine their background experience and level of visual thinking on all design aspects, including color matters. The intention of this exercise was also to lead students to a perceptual experimentation and discovery. As Albers ${ }^{30}$ suggested, such exercises places visual experience and practice before theory. The studio course finalized with a brief discussion of the posters, which were not graded.

\subsection{2 $\quad$ Exercise 2}

It was the last phase of the first studies on 2-dimensional organizations, which stretched over 3 weeks. In these exercises, firstly, the students ascertained principles of organizations by dissecting the given city plans such as Barcelona, New Mexico, Paris, and so on and consecutively transformed them into two-dimensional compositions by means of freehand drawings and black and white cut-and-paste technique after studying the regular geometries and their relations. As the exercises developed, students were given a lecture on color basics (color terminology, primary-secondary-tertiary colors, and color dimensions). Students also had to prepare Itten's color wheel and color scales for the three color dimensions (hue, chroma, and value) in gouache colors. The series ended with the Exercise 2-part of this study-that expected the students to transform their previous black and white studies into colored version on an A3 size sheet, to explore the contribution of colors to existing design. This exercise was graded where students' color use was a part of the evaluation criteria.

\subsection{3 $\quad$ Exercise 3}

This exercise was the last phase where the analytical understanding of design concepts and verbal language of design were discussed. This exercise lasted for 3 weeks after the completion of the previous series. In this exercise, the students were asked to analyze a chosen painting by different artists such as "Castle and Sun" by P. Klee, "The Knifegrinder" by K. Malevich, "Composition IX" by V. Kandinsky, and so on, then they developed their own designs. They were free to use any or all of the design tools, that is, contrast, dominance, variation, rhythm, and so on, and system of organizations, that is, central, linear, axial, and so on, within a given design field (A3 paper). The students' works were 
discussed and related critiques were given by their instructors, specifically emphasizing the conceptual, visual, relational, and practical aspects of the (basic) design elements. ${ }^{28,29,31-34}$ Previous to this exercise, students were given a lecture on color vision, color interactions, color harmony principles, and color design applications from art, design, and architecture. Thus, students were expected to create a visual organization by using the design tools and systems; supported and enriched by systematic and controlled use of color. All the abovementioned components were considered as criteria of evaluation where the students' works were graded.

\section{3 | Method and procedure}

During the study, 96 students were attending the basic design course, distributed to 3 sections which were led by 2 instructors each; following the same schedule and syllabus. The number of participants who attended all the 3 exercises included in the study and answered the questionnaire was 84. Of the 84 participants, 63 of them were female and 21 of them were male. The ages ranged between 17 and 26.78 of the participants were native Turkish speakers from different regions of Turkey. The remaining 6 were from Azerbaijan, Iraq, Kuwait, Lebanon, South Korea, and Sudan, and they answered the questionnaire in English.

After completing each exercise (but before the corresponding in-class discussion), a questionnaire was given to the students. In the questionnaire, the following open-ended questions were asked both in English and Turkish:

1. Did you establish any criteri(on/a) or reasons when choosing colors?

2. Why did you choose these colors?

3. Did you relate colors in any way with each other?

Data gathered from the questionnaire were subject to analysis.

\section{4 | Data analysis}

According to the objective of the study, qualitative analysis was made. Data obtained from open-ended questions were analyzed by extraction of themes and listed under the primary domains of preferential, symbolic, formal, systematic, and thematic categories derived from the literature. ${ }^{19,20,25,35}$ Each criterion mentioned by the subjects was documented numerically as columns, where the value "1" represented the presence and " 0 " represented the absence of the corresponding criterion, while a new criterion was noted or added under the theory driven categories as rows.

The dimensions derived from the questionnaires under the primary domains were thus data driven ${ }^{36}$ and could be termed as sub-themes. The sub-themes and their indicators were identified so that the analysis could be replicable by others, with reference to Boyatzis ${ }^{36}$ study. The analysis revealed that there was a distinction between associative symbolic meaning and emotional symbolic meaning; therefore, these aspects were separated into two major domains early in the analysis. Table 1 represents the coding procedure used in the data analysis. After the code label or theme the definition of what the theme concerns and a description of how to recognize the theme (indicators) are indicated. For data analysis and interpretations, one of the authors of this study made the translations from native Turkish to English. A professional editor also reviewed the translations.

While qualitative analysis revealed the rich and varied aspects of color decision making; use of both qualitative and quantitative data provides a more comprehensive understanding by noting trends besides knowledge of participants' perspectives, as Creswell and Clark $^{37}$ suggest. Accordingly, quantitative representation of findings is also included to allow an overview of the criteria within an exercise as well as among the consecutive three exercises.

\section{4 | RESULTS}

Initially, students' color decision making in the 3 consecutive exercises is presented, followed by a comparison of the 3 phases. Students' works are also exemplified for each exercise by quoting the associated responses. The tables that highlight the frequencies of the main themes are supported by explanations of the sub-themes that emerged from student interviews.

The following table presents the distribution of color decision making criteria among the 3 exercises.

\subsection{Color decision criteria for exercise 1}

In the first exercise, the major reasoning behind the color choices was systematic criteria, highly outnumbering all the other considerations (see Table 2). This category was followed by symbolic-associative and formal, extending to symbolic-emotional criteria, preferences and last, thematic considerations.

Systematic decision making at this stage relied on the student's prior knowledge of colors. The most emergent subtheme regarding color knowledge was "contrast," mentioned by over one-third of students. This followed the colors being in "harmony" noted by a quarter of students. While some students stated these without further explanations, others clarified their understanding with the terms "contrast of dull and vivid colors," "contrast of warm and cool," "harmony of blends," and so on. Meanwhile, a few students noted a conscious use of similar colors, fading effects of tones, as well as warm and cool colors. Student examples of the Exercise 1 are displayed in Figure 1. 
TABLE 1 Coding of data according to themes

\begin{tabular}{|c|c|c|}
\hline \multicolumn{3}{|l|}{ Label } \\
\hline \multirow[t]{2}{*}{ Preference } & Definition & Describing a color preference by the student based on subjective value \\
\hline & Indicator & Comments such as "I like," "I preferred," "it looks nice" \\
\hline \multirow[t]{2}{*}{ Symbolic-emotional } & Definition & Describing a certain color according to the feeling/emotion it arouses/expressive qualities \\
\hline & Indicator & Comments such as "lively," "refreshing," "attentive," "serene," "unhappy" \\
\hline \multirow[t]{2}{*}{ Symbolic-association } & Definition & Describing a certain color according to its association with an object/phenomenon/concept \\
\hline & Indicator & $\begin{array}{l}\text { Comments such as "my room's color," "colors of fire," "reflecting myself," "color of sky," } \\
\text { "used in everyday life," "representing nature." }\end{array}$ \\
\hline \multirow[t]{2}{*}{ Formal } & Definition & $\begin{array}{l}\text { Describing a certain choice based on formal relationships, regardless of a } \\
\text { learned theme or specific color scheme }\end{array}$ \\
\hline & Indicator & $\begin{array}{l}\text { Comments such as "the circle shape to stand out," "assigned blues to squares and reds } \\
\text { to triangles," "increase legibility of shapes," "to divide the design field into two" }\end{array}$ \\
\hline \multirow[t]{2}{*}{ Systematic } & Definition & Describing a certain choice based on a color scheme and color design principle/theory \\
\hline & Indicator & $\begin{array}{l}\text { Comments such as "tints and shades/tones of a color," "analogous," "contrast," "primary colors," } \\
\text { "monochromatic," "harmony," "neighboring colors," "triadic" }\end{array}$ \\
\hline \multirow[t]{2}{*}{ Thematic } & Definition & Describing a certain choice based on learned design compositional themes. \\
\hline & Indicator & $\begin{array}{l}\text { Comments such as "asymmetric balance," "dominance," "central," "transparency," } \\
\text { "axial," "symmetrical," "gridal" }\end{array}$ \\
\hline
\end{tabular}

These results revealed that some students had prior knowledge of contrasting colors and used it for the purposes of this exercise. Moreover, whereas a sense of color harmony was also reflected in the designs, the relevant explanation behind color harmony was not strongly established, as evident in the quote below (data analysis labeling for primary domains identified in italics):

"I wanted to show harmony of colors (systematic). The colors I used were not the ones that I had in mind when I began the project, but as I made explorations,

TA BLE 2 Students' color choice criteria in the 3 assignments (mentioned at least once)

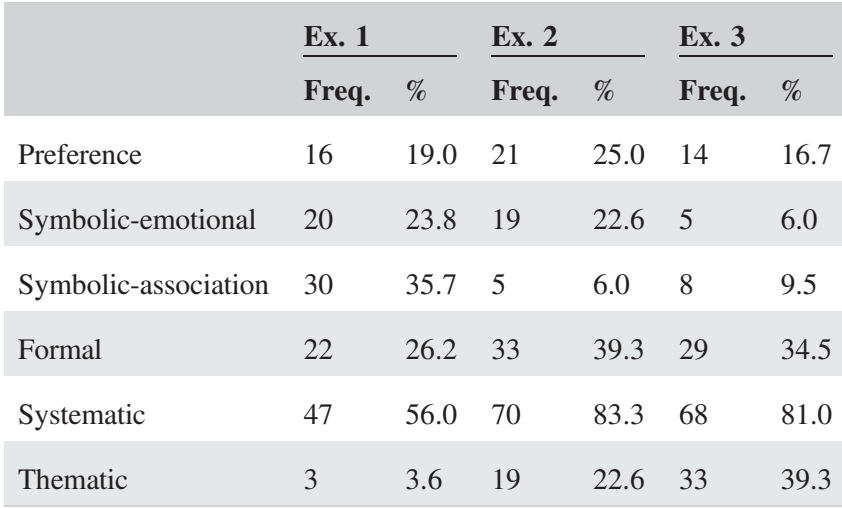

I used the colors which I discovered were vivid and attractive (symbolic-emotional). Thus, the colors I used appear harmonious next to each other (systematic)."

The symbolic-associative meanings of color choices ranged widely. About one-fifth of the students, about onefifth, independently related color choices with actual objects/ environments or conceptual entities. Singularly mentioned

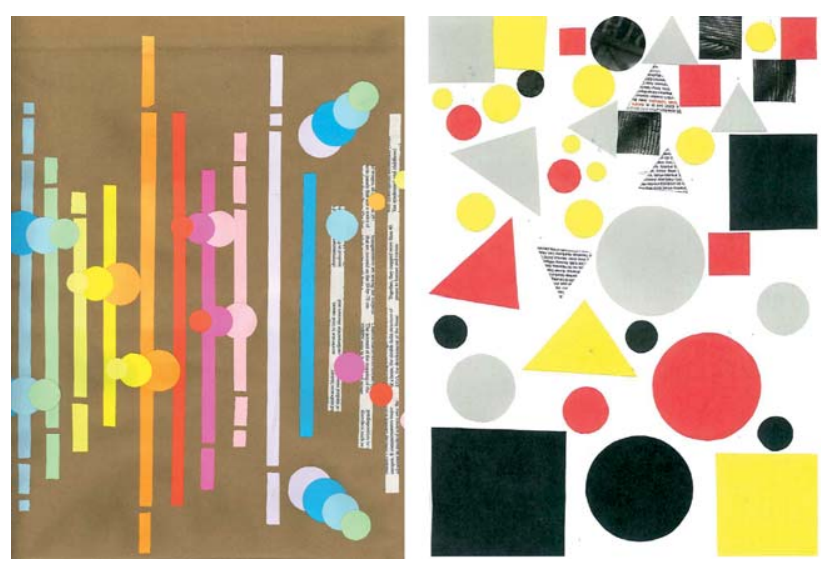

FIG URE 1 Examples from exercise 1: (left) "I want to show similarity of colors (systematic) in groups (formal). I like these colors (preference), they remind me romance (symbolic-association)." (right) "I choose colors to define the shapes on white background (formal). I want to group the same colored shapes at corners and diagonals (formal)" 
associations were colors of nature, the sea, sunset, day and night, leaves, forests, flower, fire, soil, summer, men and women; as well as life and death, lucidity, and so on. A systematic usage of colors schemes at times supported the associations towards nature:

"I used contrast colors of blue-orange and yellowpurple (systematic). I chose these colors since I wanted to represent sunset. Thus, I used the blue and purple for the sea and yellow and orange for the sun (symbolic-associative)."

Within associative meanings, around one-sixth of students mentioned that they chose colors as the expression of their identity, thus the choices were self-oriented. Students used the terms "reflecting me" or "used in everyday life." Independent associations such as hell, vintage, gothic were also mentioned.

Regarding formal decision criteria, the majority of students chose specific colors for formal referencing; that is, coding and grouping of shapes. Sometimes students chose certain colors relating them to the formal characteristics of shapes, and as such grouped them accordingly:

"I chose predominantly red because I relate it with triangles (formal). Thus, triangles have sharp corners and transitions and I feel they are ideal for the tough (symbolic-associative)."

Moreover, references were made to figure-ground relationships and the design field. Colors were intentionally located with respect to the center or corners of the design field. Some also used color contrast to reflect the difference of figure and ground.

Regarding symbolic-emotional meanings of colors, students identified certain affective attributes to colors, which included both positive and negative emotions. Usually, terms such as: "soothing," "softness," "purity," "love," "serenity," "infinity," "self-respect" were used and connected with colors such as white, blue, and primarily light colors. On the other hand, dark colors were related to "conflict," "unhappiness," "anxiety," "toughness," and so on.

Besides the apparent emotional tones, a number of students chose a color because it was "attentive" and "attractive" or "lively" (the term canlı in Turkish means both "bright" and "lively"). Thus, the intensity of the color was associated with the effect that it delivered to the viewer.

For preferential selections, the majority of students reasoned their color choice with the terms "I like...," "it seems good." At times, preferential selections accompanied symbolic associations; both self-referential and referring to certain concepts:
"My main criterion is the colors being bright and I like bright colors (preference). Blue represents infinity and self-confidence (symbolic-associative, emotional). Moreover, I usually use blue in my clothing, while my room-which I decorated-is a combination of white and purple colors (symbolic-associative)."

However, a few students also stated that they had no specific color decisions, and their choice was arbitrary and random. One student noted that he preferred to mix colors randomly and see the results. Finally, some students used certain colors due to practical constraints and purposes; they used the color palette and material available to them at the time.

Only 3 students mentioned thematic considerations in the first phase. Since design themes were not introduced as part of the problem in this stage, using color to emphasize thematic design decisions was seldom considered. They mentioned unity, variation and complexity as reasons for their color choices.

\section{2 $\quad$ Color decision criteria for exercise 2}

Similar to the previous exercise, the major reasoning behind the color choices in this stage was again students' systematic criteria; however, the number of students that had systematic considerations increased from $56 \%$ to $83.3 \%$. This followed formal criteria. Preferences, systematic-associative criteria, and thematic aspects were also considered by about onefourth —of the students. Moreover, there was a large decrease in symbolic-associative criteria which only few students considered (a decrease from $35.7 \%$ to 6\%) (see Table 2).

Within systematic decision criteria at this stage, similar to the previous stage, the predominant choice was contrasting colors, used by one-third of the students. On the other hand, the use of analogous/similar colors emerged, used by a quarter of the students. These two main choices were followed by monochromatic color schemes, indicated by "changing from light to dark," "mixing primaries with white," "gradual change of tones," "fading colors," and "monochromatic." A few students also mentioned using primary colors, colors as they related within the color wheel, using certain mixtures, and cold and warm colors. Student examples of the Exercise 2 are displayed in Figure 2.

In this exercise, an increase in the variations of systematic color choices was observed, compared to the previous exercise. Moreover, there was a decline in the vague use of the word "harmony," which was previously apparent, giving way to more specific explanations of how colors were used: 

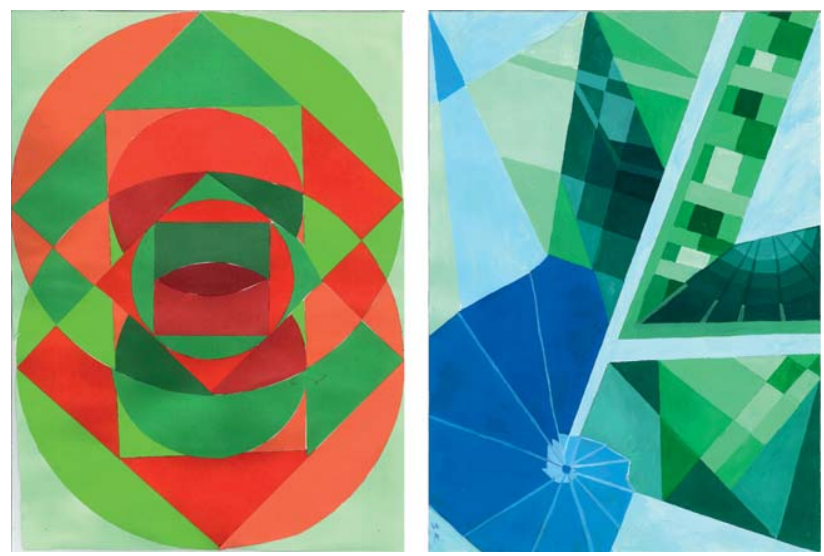

F I G U RE 2 Examples from exercise 2: (left) "I used contrast colors (systematic) that I like very much (preference). They are getting light toward the corners (formal)." (right) "In my work I have two design principles; grid and off-center. I matched grid with green and off-center with blue (thematic). The tints of blue are related to size (systematic), while the tones of green are to show rhythm (thematic)

"The appearance of how colors come together alongside each other in harmony is important as they should not strain the eyes. First, I chose primary colors and then mixed them together. At some areas, they were mixed with white to create tints (systematic)."

The formal color criteria, similar to the previous exercise, were predominantly based on grouping, relating to their own shapes and sizes and/or related to the design field. Moreover, considering the design field and the figure-ground relationship, students made conscious color decisions, such as locating different colors on the upper and lower half of the field, at the center or at a corner. Occasionally, colors were used to emphasize shapes, sizes, and increase legibility. As such, systematic knowledge sometimes supported the formal decisions as the following excerpts show:

"I used contrasting and analogous colors and grouped them together accordingly (systematic, formal)."

"I tried to use contrast colors at one side of my design and in order to emphasize the relation between two different fields, I used the same color (green) and their complementary colors (systematic, formal)."

There was a slight increase in the number of students, around one-quarter, who chose colors due to preference. Many students commented that they "liked" a color, and/or thought it looked nice/beautiful. However, three students noted that they did not have a specific reason behind their choices, whereas 2 students used colors due to their availability or limitation.

Students' thematic considerations increased greatly, reaching about a quarter of students in this second exercise.
Here, students began consciously using color to indicate systems of organizations, such as emphasizing a central, axial, or asymmetrical organization. As such, a systematic color use complemented the organizational principles. For example, while some students used contrast to emphasize the center, other used primary colors at the center. Showing the gridal system or axiality through color choices was also specified:

"I used analogous colors because I did not want to destroy the harmony of my axial organization by contrast colors (systematic, thematic). When we use contrast colors, it seems to contradict to the designs unity and breaks the design to pieces, so I used the neighboring colors in the color wheel which are in harmony with one another (systematic)."

In this phase, symbolic-emotional meanings assigned to color choices continued. Students chose colors for their liveliness, attractiveness, energetic look, or ability to receive attention. Words such as "serene," "soft," "calming" were also used as attributes of certain colors.

Symbolic-associative meanings emerged the least often. In this phase, the self-associated attributes did not emerge, and the associative meanings were confined to relations to nature, sunset and sunrise, and temperature.

\subsection{Color decision criteria for exercise 3}

As per previous 2 exercises, the major reasoning behind the color choices in this stage was systematic, followed by a large increase in thematic criteria. This followed formal concerns and preferences. There were few students who assigned symbolicassociative meanings to colors, and even fewer who had symbolic-emotional criteria (see Table 2). As seen from Table 2 , while there were slight differences of increase or decrease in systematic, formal, and symbolic-associative use of color as compared to the previous exercise, there was a $16 \%$ increase in the use of color for thematic reasons, and a considerable drop in students' symbolic emotional attributes up to $16 \%$. Moreover, the preferential use of color was observed the least in this phase in comparison with the previous two phases, although it still remained higher than both symbolic color choices.

Within systematic decision criteria at this stage, contrast continued to be a frequently used decision criteria, by over a third of students. Moreover, students made more elaborate decisions regarding contrasting colors; such as using both achromatic and complementary contrasting colors, contrast of chromatic values, and so on. Contrast color usage was followed by the usage of monochromatic colors, and the use of analogous/similar colors. Thus, "tints" and "shades" of multiple colors, "gradations from light to dark" and "achromatic colors" were determined by students. Triadic and primary 


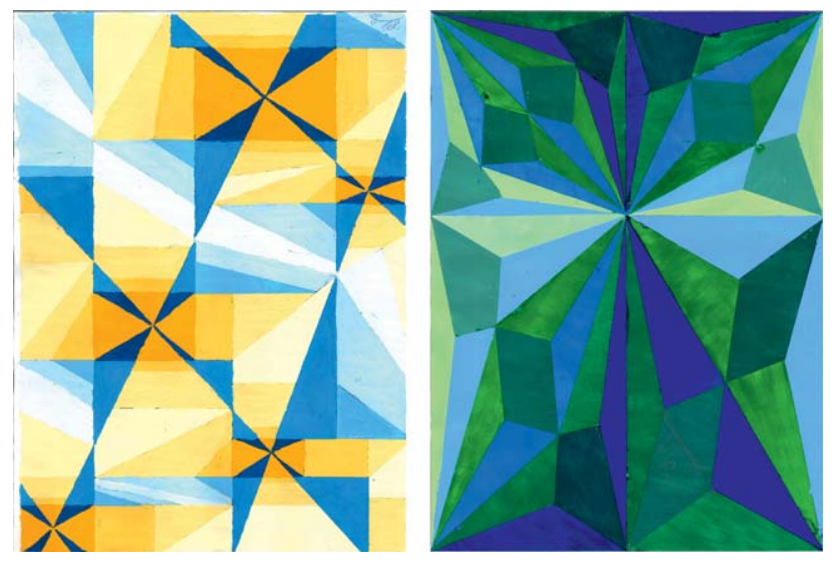

F I G U RE 3 Examples from exercise 3: (left) "I choose my colors in order to emphasize the layers of my design (thematic). Light blue and light yellow colors are for the lowermost layers of a grid (systematic). Blue is getting purplish, and yellow is getting near to orange toward the uppermost layer to mark the groups' centers (systematic, formal). These variations help me to enrich 3-dimensional layers in my design (thematic)." (right) "I used similar colors for unity (systematic). I differentiate horizontal and vertical groups by light and dark tones, and their transitions (formal, systematic). Blue and green is my favorite color combination (preference)"

color schemes were chosen by 6 students each. "Harmony" was still a term used to denote the reason to choose a certain color scheme. Thus, in this stage the variety and number of color schemes used by the students was observed to increase as compared to previous exercises. Student examples of the Exercise 3 are displayed in Figure 3.

In this stage, thematic use of color seemed to be the highest among the 3 phases. Around one-fifth of students made general statements referring their color choices to "emphasize," "enrich," and "express" their design ideas/organizations. Specific objectives included using color to express order, hierarchy, changing rhythms, repetition. Detailed explanations regarding organizational principles were apparent:

"I wanted to create layered organization. I used the light pink and red which seemed similar in tones as the background layer (systematic), and dark pink colors to emphasize the 'off-centered' organization layer in the foreground (thematic)."

As seen above, thematic decision was often accompanied with systematic use of color. For example, monochromatic color schemes were used in favor of expressing change in size or rhythmic relations of shapes, whereas contrasting colors were used to define layers, focal points, a central organization etc.

Regarding formal decision criteria, while over a quarter of students used colors to increase the identity and legibility of forms, others used colors for grouping and coding. Zoning and relating to figure-ground relationship was less frequently noted.
Color decision criteria often supported each another. In this third stage, the number of analytic criteria chosen for a design increased and became interrelated, as evident in the following excerpt:

"I chose triadic colors, since it allows more opportunities for colors and their tones (systematic). I chose them due to the color harmony. I used them in order to prevent the loss of identity of the shapes (formal) and also emphasize the symmetry of the organization (thematic)."

Along with a wide array of thematic, systematic, and formal considerations, which were at this stage expected from the students, preference still continued to be a reason for color choice. Students dominantly chose colors because they liked them and looked good. While the availability of material and easiness of use was still apparent, this was accompanied by the students' preferred use of certain colors as per their previous work.

The few the symbolic-associative meanings assigned to colors ranged from a relationship with the nature and the sea, as well as relationship to the city. Thus, the associations were related to the subject of the exercise given; as students made abstractions from city plans:

"As we are creating a new organization about a city, I wanted to use green and blue and their combination like in a natural environment (symbolic-associative). I wanted to use the two colors that we see in nature. From inside out, the tones of the colors darken (systematic)."

"I associated the colors with the colors of the city. I wanted them to look harmonious and realistic. I used the tones of colors ranging from light grey to very dark grey (symbolic-associative, systematic)."

Meanwhile, symbolic-emotional criteria were mostly characterized as the color being lively, warm, energetic and likely to attract attention:

"Yellow and red are energetic and attentive colors. When their contrasts are included in the project, the energy of the organization increased immensely. The reasons I chose these colors were to awaken the lively and energetic emotions of the viewer (systematic, symbolic-emotional)".

\subsection{Comparing the three exercises}

From a general viewpoint, the data revealed the transformation of students' color choices while creating two- 
TABLE 3 Heuristic and analytic decision making in the three assignments

\begin{tabular}{|c|c|c|c|c|c|c|}
\hline & \multicolumn{2}{|l|}{ Ex. 1} & \multicolumn{2}{|l|}{ Ex. 2} & \multicolumn{2}{|l|}{ Ex. 2} \\
\hline & Freq. & $\%$ & Freq. & $\%$ & Freq. & $\%$ \\
\hline $\begin{array}{l}\text { Heuristic (at least one of preference, } \\
\text { symbolic criteria) }\end{array}$ & 59 & 70.2 & 41 & 48.8 & 28 & 33.3 \\
\hline $\begin{array}{l}\text { Analytic (at least one of formal, } \\
\text { systematic, thematic criteria) }\end{array}$ & 56 & 66.7 & 77 & 91.7 & 81 & 96.4 \\
\hline
\end{tabular}

dimensional design problems across the course of an introductory design schedule. When we observed the findings (see Table 2), considering heuristic criteria, initially, students select colors due to their personal preferences steadily in all 3 phases. Thus, liking certain colors, viewing them as beautiful, and/or using them due to material availability and ease of use were prevalent throughout their design progress. On the other hand, we saw a decrease in symbolic-emotional and symbolic-associative criteria passing from the first phase to second and/or third phases. Thus, in the final phase, symbolic meanings assigned to colors have decreased and give way to analytic criteria.

Within the analytical outlook, students in all exercises predominantly applied systematic criteria related to color, with a large increase in the number of students passing from first exercise to the second. Meanwhile, formal criteria also existed in a large amount consistently throughout the phases. However, we observed very few thematic considerations in the first phase, with steady increase in the second and third phases. Thus, as new knowledge related to both color systems as well as organizational principles were introduced, these were consistently applied by students in their designs.

In addition to analyzing primary domains, an overview of students' tendencies in color decision making via heuristic and analytic criteria can also be made. Table 3 represents the findings of number and percentage students applying at least one heuristic decision making criteria-preference, symbolicemotional, and symbolic-associative - and at least one analytic decision making criteria-formal, systematic, or thematicduring the 3 exercises (see Table 3 ).

Initially, as seen in Table 3, students are observed to have applied approximately equally one or more of heuristic (70.2\%) and analytic reasoning criteria $(66.7 \%)$ at the initial stage of design. Thus, analytic criteria were prevalent even prior to being informed about color theory or being exposed to evaluation criteria by the instructors. However, as the learning progresses, while the heuristic criteria decreased $(48.8 \%$ at phase 2 and $33.3 \%$ at phase 3), application of analytic reasoning increased $(91.6 \%$ at phase 2$)$ whereas almost all students applied at least one analytic criteria in the final stage (96.4\%). Thus, while analytical reasoning increased with the introduction of color theories, methodologies, and knowledge-base, intuitive and subjective reasoning around color choices did not diminish. For many students, they coexisted and supported one another during decision making.

During data analysis, we viewed an increase in the richness and complexity of student decision making criteria as they progressed in the three stages. Therefore, we found it crucial to present this via observing the number of criteria considered by the students in the 3 assignments as seen in Table 4.

The results indicated that students applied an increased number of criteria as the studio progressed and therefore did not depend on one reason when applying their color designs. Thus, Table 4 displays that, while $47.6 \%$ of students applied only one criteria in the first exercise, this decreased to $31 \%$ and $23.8 \%$, respectively. On the contrary, those that applied more than 2 criteria increased from $53.4 \%$ in the first exercise to $69 \%$ in the second. Eventually, in the final exercise, students had obviously acquired a more complex and varied color selection set, with $76 \%$ of them applying two, three of four criteria. Thus, an increase of $23.8 \%$ in the number of students was observed who have more than two color decision criteria. Although an increase of the level of complexity of their projects with the progression of exercises was expected, the number of criteria was not a significant aspect in discussions. As such, this rise indicated the application of color criteria in combination with the design/organizational principles during a series of ongoing exercises and the students' exposure to different examples through research and peers work.

Parallel to the rise of the number of color decision criteria, an increase in the range of color schemes within systematic usage was observed. Thus, while some systematic criteria seemed to exist in all stages, others schemes appeared only in the second and third stages. For example, students

TABLE 4 Amounts of students' color choice criteria in the three assignments

\begin{tabular}{|c|c|c|c|c|c|c|}
\hline \multirow{2}{*}{ \# of criteria } & \multicolumn{2}{|l|}{ Ex. 1} & \multicolumn{2}{|l|}{ Ex. 2} & \multicolumn{2}{|l|}{ Ex. 3} \\
\hline & Freq. & $\%$ & Freq. & $\%$ & Freq. & $\%$ \\
\hline 1 & 40 & 47.6 & 26 & 31.0 & 20 & 23.8 \\
\hline 2 & 36 & 42.8 & 37 & 44.0 & 43 & 51.2 \\
\hline 3 & 6 & 7.1 & 19 & 22.6 & 21 & 25 \\
\hline 4 & 2 & 2.4 & 2 & 2.4 & 0 & 0 \\
\hline
\end{tabular}


knew about contrasting colors and used them even in the initial stage. However, there was a striking increase in the application of monochromatic color schemes and analogous color schemes in the final two stages. These not only enabled students to create more complex designs, but also supported formal and thematic concerns, particularly in the third assignment. These findings clarified which of the aspects of students' color knowledge come from pre-education and which are cultivated during color design education.

\section{5 | DISCUSSION}

This study investigated the progression and cultivation of introductory design students' attitudes toward color design decisions. For the study, 3 two-dimensional colored exercises, which are critical in terms of the phases of color education, were chosen and the students' color design decisions were identified as codes and themes under 6 primary categories.

The primary categories of color decision making were taken from the literature ${ }^{12,16,19,20,25}$ and titled as preferential, symbolic, formal, systematic, and thematic. The analysis also revealed a distinction between symbolic-associative meaning and symbolic-emotional meaning in color decisions. Preferential (color preferences) and symbolic attitudes (color associations/connotations and color emotions) included sets of personal, subjective, and intuitive criteria and were categorized under heuristic decision making criteria. Formal, systematic and thematic aspects that include thinking, reasoning and knowledge, were categorized as analytic decision making criteria.

The findings of this study showed that the initial attitudes of the (basic) design students in color decisions involve both heuristic and analytic aspects at the first phase. While the students' analytical abilities increased in time through color education - as expected, their heuristic decisions did not disappear completely. The findings also indicated the presence of the emergent sub-themes pertaining to the major themes of color criteria used by the students.

As heuristic criteria, preference was apparent in all stages, however symbolic (both emotions and associations) criteria decreased while color education progressed. In terms of analytic criteria, systematic and formal use of color emerged in the first stage, while systematic criteria showed an increase at the second and third stages. Formal and systematic color aspects are based on visual and perceptional characteristics of color and color compositions, regarding both the students' previous knowledge and intuitive practices about color, and the aspects that are acquired subsequently through education. Systematic color decisions encouraged visual thinking and reasoning in color design through applying color theories and color composition principles. Thematic attitudes in color decisions became a major part of the stu- dents' design considerations at the last phase, most probably due to the dependence of a design theme or concept on the principles of organization.

The categories mentioned in this study are coherent partially with those introduced by Portillo and Dohr, ${ }^{9}$ who established 5 categories of color planning criteria used by designers: compositional, symbolic, behavioral, preferential, and pragmatic. Behavioral and pragmatic criteria used by the mentioned study, which do not emerge either from function or real-life architectural design context were not the concern of this study. This study contributes to the knowledge of novice designers' color decision criteria and its progression, before constraints with respect to context and function of an interior (architectural) design problem becomes part of color decision making which are considered in earlier studies. ${ }^{9}$ The results yield emergent sub-themes within the major domains of color selection that contribute to existing knowledge.

This study also showed a significant increase in the number of criteria mentioned by students during the progression of their color education, indicating that design students immediately begin to think about and make decisions using the various and complex mechanisms they have learned. Each student absorbs and applies that knowledge slightly differently, bringing a diversity of solutions to the assigned design problems that are appropriate to the nature of design. While the color criteria in each design phase increases in complexity, student comments also reflect the support and interrelations of one criteria with another; such as preference and symbolic-emotional or thematic and systematic. It can thus be said that students' intuitive, subjective, and heuristic attitudes are supported and rationalized by their objective, knowledge-based, and analytical attitudes acquired during color education. This finding seems to indicate a more complex decision making process particularly in color design, ${ }^{9-13,35}$ comply with multiplistic thinking, ${ }^{38}$ and different than linear decision making. ${ }^{11}$ However, for each student, analysis of further statistical relation(s) between the criteria within each phase as well as the repetition or continuation of certain categories over the course of three exercises was beyond the scope of this study. Moreover, the current findings related to student perspectives across the 3 phases should be taken as trends, paving way for explorations within other educational contexts and large number of students. Thus, further studies would reveal additional insights into the range, depth and associations of choices.

McLachlan and McLachlan ${ }^{11}$ suggested that color theory has to embody a framework that not only relies on analytical and rational decision making but also heuristic modes that comprise individual beliefs, attitudes, and previous knowledge of designers; which is already the case in architectural practice. As such, as this study indicates, although the current basic design education encourages scientific and 
systematic color knowledge use and application, educational strategies should be developed to incorporate explicitly students' subjective decision making so that the potentialities of such a use can also be sought. Janssens and Mikellides ${ }^{5}$ indicate the lack of students' knowledge about color in architectural education. The findings of this study also imply that the theoretical knowledge on color is being used by the students even at introductory stage of design education. The verified concurrency of heuristic attitudes and analytic decision making in color design by this study supports that architectural color requires its own body of literature in the context of education as well. In this respect, color theory and research are suggested to be a part of the curriculum in all related courses, and to be involved in design studios as an integral part of exercises and projects.

These findings may also lead to some complementary discussions about color in design education and illuminate the progression and cultivation of design students' views around color over the methods of education. In this respect it can be said that, design exercises formulated to uncover students' both heuristic attitudes and the knowledge gained enhance the progression of color decision making during their education. The method of studio learning already facilitates an environment for students to explore themselves, stimulating their heuristic attitudes and encouraging them to adapt what they recently learned. Studio learning may be enhanced with additional theoretical support such as lectures, reflections and discussions to embrace the project based methodology.

In this study, color design works were exemplified in 2dimensional abstract compositions, regardless of architectural context. Further longitudinal studies would reveal changes in color decision making in the later stages of design education, particularly regarding 3-dimensional space composition, ${ }^{39}$ functional behavior, ${ }^{9}$ and other contextual concerns. ${ }^{35,40}$ Drawing upon literature on application of color theory in art, design and architecture, this article underscores the understanding of students' color decision making in a coherent and systematic framework.

\section{ACKNOWLEDGMENTS}

The authors are thankful to the Basic Design I instructors of Interior Architecture and Environmental Design Department, and the students of Faculty of Art, Design and Architecture, Bilkent University, for their supports in 2015-2016 fall semester.

\section{REFERENCES}

[1] Light W. Uncolored color: the subjective syndrome and the objective objective in teaching architectural color design. In: Proceedings of the International Color Association (AIC) Symposium: Color in Environmental Design, August 8-11, 1988; Winterthur Polytechnic, Switzerland.
[2] Adams E. The elements and principles of design: a baseline study. Int J Art Design Educ. 2013;32:157-175.

[3] Green-Armytage P. The value of knowledge for color design. Color Res Appl. 2006;31:253-269.

[4] Bergström B. Creative color education. In: Proceedings of the 9th Congress of the International Color Association (AIC), SPIE Vol. 4421, June 24-29, 2001; Rochester, New York:963-966.

[5] Janssens J, Mikellides B. Color research in architectural education-a cross-cultural explorative study. Color Res Appl. 1998; $23: 328-334$

[6] Ünver R. Color education in architecture. In: Proceedings of the 9th Congress of the International Color Association (AIC), SPIE Vol. 4421, June 24-29, 2001; Rochester, New York:10001003.

[7] Akbay YS, Durão MJ. Color harmony: ideality of pleasurableness. In: Monteiro MR, Kong M, Neto MJP, editors. Utopia(s) -Worlds and Frontiers of the Imaginary. London: Taylor \& Francis Group; 2016:193-198.

[8] O'Connor Z. Color harmony revisited. Color Res Appl. 2010;35: 267-273.

[9] Portillo M, Dohr JH. A study of color planning criteria used by noted designers. J Interior Des. 1993;18:17-24.

[10] Smith D. Environmental coloration and/or the process. Color Res Appl. 2003;28:360-365.

[11] McLachlan F, McLachlan E. Color and contingency: theory into practice. Arch Theory Rev. 2014;19:243-258.

[12] Akbay S. An analysis of basic design students' intuitive and analytic attitudes in color decisions. (Unpublished master's thesis). Ankara: Bilkent University; 2003.

[13] Serra J. Three color strategies in architectural composition. Color Res Appl. 2013;38:238-250.

[14] Lang J. Symbolic aesthetics in architecture: toward a research agenda. In: Nasar JL, editor. Environmental Aesthetics: Theory, Research and Applications. New York: Cambridge University Press; 1992:11-26.

[15] Nasar JL, editor. Environmental Aesthetics: Theory, Research and Applications. New York: Cambridge University Press; 1992.

[16] Ritterfeld U. Social heuristics in interior design preferences. J Environ Psychol. 2002;22:369-386.

[17] Kaplan S. Where cognition and affect meet: a theoretical analysis of preference. In: Nasar JL, editor. Environmental Aesthetics: Theory, Research and Applications. New York: Cambridge University Press; 1992:56-63.

[18] Palmer SE, Schloss KB, Sammartino J. Visual aesthetics and human preference. Ann Rev Psychol. 2013;64:77-107.

[19] Klaczynski PA. Framing effects on adolescent task representations, analytic and heuristic processing and decision making implications for the normative/descriptive gap. Appl Dev Psychol. 2001;22:289-309.

[20] Kokis JV, Macpherson R, Toplak ME, West RF, Stanovich KE. Heuristic and analytic processing: age trends and associations with cognitive ability and cognitive styles. J Exp Child Psychol. 2002;83:26-52.

[21] Evans JBST, Over DE. Reasoning and Rationality. Hove: Psychology Press; 1996. 
[22] Farivarsadri G. An Analytical re-assessment of introductory design in architectural education (Unpublished doctoral dissertation). Ankara: Bilkent University; 1998.

[23] Koyuncugil HT. An analysis of preference formation in introductory design education (Unpublished master's thesis). Ankara: Bilkent University; 2001.

[24] Droste M. Bauhaus 1919-1933. Köln, Germany, Taschen; 2002.

[25] Parsons MJ. A suggestion concerning of the development of aesthetic in children. J Aesthet Art Critic. 1976;34:305-314.

[26] Lee N. Project methods as the vehicle for learning in undergraduate design education: a typology. Des Stud. 2009;30:541-560.

[27] Altay B. User-centered design through learner-centered instruction. Teach Higher Educ. 2014;18:138-155.

[28] Wong W. Principles of Two-Dimensional Design. New York: Van Nostrand Reinhold; 1972.

[29] Ching FDK. Architecture: Form, Space and Order. New York: Van Nostrand Reinhold; 1979.

[30] Albers J. The Interaction of Color: Revised and Expanded Edition. New Haven: Yale University Press; 2006.

[31] Linton H. Color Model Environments: Color and Light in ThreeDimensional Design. New York: Van Nostrand Reinhold; 1985.

[32] Arnheim R. The Power of the Centre: A Study of Composition in the Visual Arts. Berkley: University of California Press; 1988.

[33] Bevlin M. Design Through Discovery. Fort Worth: Harcourt Brace; 1989.
[34] Bowers J. Introduction to Two-Dimensional Design: Understanding Form and Function. New York: John Wiley \& Sons, Inc; 1999.

[35] Ural SE. Color in architecture: Effects of color dynamics on coloring artificial environments. (Unpublished PhD. Dissertationin Turkish). Trabzon: Karadeniz Technical University; 1995.

[36] Boyatzis RE. Transforming Qualitative Information: Thematic Analysis and Code Development. Thousand Oaks: Sage Publications, Inc; 1998.

[37] Creswell JW, Clark VLP. Designing and Conducting Mixed Methods Research. London: Sage; 2007.

[38] Carmel-Gilfilen C, Portillo M. Developmental trajectories in design thinking: an examination of criteria. Des Stud. 2010;31: 74-91.

[39] Ural SE, Yilmazer S. The architectural color design process: an evaluation of sequential media via semantic ratings. Color Res Appl. 2010;35:344-351.

[40] Elliot AJ, Maier MA. Color-in-context theory. Adv Exp Social Psychol. 2012;45:61-125.

How to cite this article: Ural SE, Akbay S, Altay B. Progression of color decision making in introductory design education. Color Res Appl. 2017;42:849-860. https://doi.org/10.1002/col.22129 